\title{
Lektur Agama Dalam Bentuk Kaset di Sulawesi Selatan
}

\section{Oleh : Arifuddin Ismail}

Mcnjclang akhir abad XX, telah terjadi pcrkembangan dan pergeseran di berbagai aspck kehidupan secara cepat, terutama di bidang science dan tcknologi. Gerak dari bidang ini sangat mempengaruhi pula pergeseran dan pcrkembangan pada sektor lain. Ini tidak dapat dihindari, karcna hasil science dan tcknologi. Gerak dari bidang ini sangat mempengaruhi pula pergeseran dan pcrkembangan pada sektor lain. Ini tidak dapat dihindari, karena hasil science dan tcknologi pemanfaatannya bersentuhan langsung dengan manusia.

Pesatnya arus perubahan terscbut, scmakin membuka peluang yang lebih besar akan kebutuhan terhadap berbagai bentuk tcknologi, utamanya teknologi komunikasi dan informasi, sepcrti yang dipakai pada media cetak dan elcktronik (radio, telcvisi dan sebagainya) beserta perangkatperangkatnya. Ini dinilai sangat penting sebagaialatpemenuhankebutuhannya, terutama kebutuhan mental (Susanto 1975 : 2).

Khusus mengenai pemakaian radio dan pcrangkatnya, yaitu kaset, dalam satu dasawarsa tcrakhir ini scmakin banyak peminatnya, mulai dari anak-anak, rcmaja atau kaum muda maupun orang tua. Media ini telah terscbar ke pclosok desa; dan pada scbagian warga masyarakat menjadikannya sebagai simbol status sosial.

Di sisi lain, radio dijadikan sebagai medium da'wah efektip dalam membentuk kepribadian baik secara kollekuf maupun individu. Olch karena itu, sesuai dengan pcran yang dibawakan untuk percepat penyebaran ide \& perubahan serta pembentuk kebudayaan (Susanto 1975:147).Pesanpesan keagamaan secara intensif dapat disuarakan dan dipancarkan melalui saluran ini.

Mcnyadari pcran yang strategis itu, beberapa lembaga da'wah dan individu (perscorangan) yang punya kcpedulian terhadap pengembangan da'wah, berupaya memproduksi secara besar-besaran rekaman kaset yang di dalamnya berisi pesan da'wah, baik dalam bentuk lagu, pengajian maupun ccramah agama. Oleh karena itu, dalam era globalisasi sepcrti sekarang ini, kaset menjadi salah satu alternatif pilihan alat transmisi \& transformasi informasi serta medium sosialisasi nilai-nilai agama, terutama untuk mendukung pembangunan bangsa.

Upaya ini juga merupakan realisasi dari niat dan sikap baik pemerintah yang selalu mcmberikan peluang dan peranan lebih besar kepada para muballigh dalam proses pembangunan bangsa dewasa ini (AlRasyid dkk $1987: 6$ ).

Dalam rangka itu penclitian dilakukan dengan memfokuskan diri pada "Scjauhmana pcrkembangan lektur keagamaan dalam bentuk kaset yang terscbar di masyarakat". Penclitian akan dijadikan bahan masukan untuk kepentingan pengambilan kebijakan, disamping untuk menambah khasanah kclckturan.

Lokasi penclitian terscbar di $5 \mathrm{Ka}$ bupaten di Sulawesi Selatan, yaitu :'Ujung Lero Kabupaten Pinrang; Kabupaten Gowa: 
Kelurahan Sabbangparu Kotip Palopo; Bajoe Kabupaten Bone; dan Kel.Layang Kotamadya Ujungpandang.

Pemilihan lokasi ini dimaksudkan untuk melihat variasi penyebaran kaset kcagamaan di daerah, dengan asumsi bahwa di lokasi tersebut penyebaran dan pemakaiankasctlebihtinggidibanding yang lain. Di lokasi ini pula terdapat stasion pemancar radio amatir (radam) yang biasa menyiarkan acara keagamaan.

Dalam penjaringan data, kaset-kaset yang tersebar dikumpul dan direkam ulang, baik kaset yang tersimpan di masjid, radio amatir maupun yang ada di rumah-rumah penduduk. Untuk kepentingan pelaporan, dilakukan content anaiisis pada sctiap kaset, kecuali yang matcri atau isinya sama.

\section{II}

Meningkatnya pemakaian kaset adalah pertanda adanya rcflcksi dari proses transformasi sosial budaya masyarakat. Disamping sebagai salah satu indikator dari terjadinya pcrsentuhan dengan modcrnisasi. Tidak tcrkccuali pada subyek masyarakatnya, baik dilihat pada slratifikasi (kelas)'maupun dilihat pad gcografisnya. Sepcrti halnya Ujung Lcro dan Bajoe dengan komunitas pantainya (nelayan), Tompobulu Gowa dengan komunitas petaninya, Sabbangparu Palopo dengan komunitas pegawai dan pedagangnya, serta Ujung Tanah Kodya Ujungpandang dengan komposisi masyarakat yang heterogen.

Penyebaran kaset kcagamaan pada masyarakat, tidak lagi terbatas hanya di radio-amatir yang dalam waktu-waktu tcrtentu menyiarkan secara luas. Tidak juga hanya di masjid-masjid yang setiap waktuwaktu shalat mengumandangkan lewat mikrophon. Tetapi sudah merambat ke pemukiman penduduk, di pasar, kios-kios, bahkanjuga di kendaraan beroda empat dan perahu penangkap ikan yang setiap saat dilantunkan scsuai kebutuhan.

Walaupun penyebaranny sudah menjalarkemana-mana, tetapi kuantitasnya masih terbatas. Secara keseluruhan kaset keagamaan yang ditemukan di 5 lokasi pcnelitian bcrjumlah 359 buah; belum termasuk kaset-kaset yang berisi paket khusus, yaitu "Dirasah Islamiyah" yangdi dalamnya terdapat 30 buah kaset. Paket khusus ini terdapat di 2 lokasi, kecuali KMUP Lcro Pinrang dan Tompo Bulu Gowa, namun jumlahnya hanya 4 paket, 3 di Sabbangparu Palopo, dan satu paket di Bajoe Kabupaten Bone.

Pada sisi lain, pemilikan kaset juga belum merata, masih dikuasai olch orangorang yang "punya kesanggupan" atau para clit masyarakat. Persoalannya tidak terletak pada ada-tidaknya kaset-kaset beredar di pasaran, tetapi bergantung juga pada tingkat pemilikan radio dan daya beli masyarakat. Dan yang lebih penting lagi adalah kepedulian, kemauan dan molivasinya. Ada kenyataan yang dapat dijadikan bukli, bahwa bcrapa banyak penduduk yang mcmiliki radio tape dan sanggup membeli scjumlah kaset. namun sedikit diantaranya yang memiliki kaset-kaset keagamaan. Ini adalah suatu f'enomena kchidupan sosial yang disebut olch Parsons adalah "Sebuah sistcm kchidupan dari sebuah tipe tertentu (IAIN CRAIB 1986 : 58).

Kaset kcagamaan yang beredar di masyarakatjenisnyacukupbcrvariasi, mulai 
dari kaset shalawat, azam, pengajian alqur'an hingga ke ceramah agama. Dari 359 buah kasct,222 (61.83\%)diantaranyaberisi kasct ceramah agama, 64 buah (17.82\%) kaset pengajian alqur'an, 37 buah $(10.30 \%)$ lagu kasidah, 18 buah $(5.01 \%)$ kaset shalawat dan 18 buah (5.01\%) kaset azan. Gambaran jenis kaset dan lokasi tcrdapatnya kaset, diurai dalam tabel bcrikut ini. ukuran masyarakat kecil, lagi pula tidak dapat dibcli perbuah (1 kaset), karena telah terpakct dalam salu kopor.

Variasi tersebut bukan hanya dari segi jenis, tetapi dari segi maleri atau isinyajuga bcragam, kecuali kasct shalawat dan azan yang semuanya sama. Khusus kascl ceramah agama, kasidah dan pengajian alqur'an maleri isinya memang cukup ber-

\begin{tabular}{|c|c|c|c|c|c|c|c|}
\hline 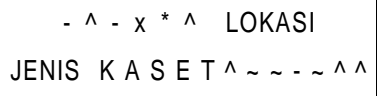 & $\begin{array}{l}\text { LERO } \\
\text { Png }\end{array}$ & $\begin{array}{l}\text { S. Paru } \\
\text { Palopo }\end{array}$ & $\begin{array}{l}\text { T. Bulu } \\
\text { Gowa }\end{array}$ & $\begin{array}{l}\text { Bajoe } \\
\text { Bone }\end{array}$ & $\begin{array}{l}\text { Layang } \\
\text { KMUP }\end{array}$ & $f$ & $\%$ \\
\hline 1. Ceramah Agama & 5 & 13 & 14 & 144 & 46 & 222 & 61.83 \\
\hline 2. Pengajian & 4 & 19 & 10 & 13 & 18 & 64 & 71.82 \\
\hline 3. Kasidah & 3 & 2 & 12 & 7 & 13 & 37 & 10.30 \\
\hline 4. Shalawat & 1 & 3 & 4 & 4 & 6 & 18 & 5.01 \\
\hline 5. Azan & 1 & 3 & 4 & 4 & 6 & 18 & 5.01 \\
\hline JUMLAH & 14 & 40 & 44 & 172 & 89 & 359 & 100 \\
\hline
\end{tabular}

Variasi di alas sangat ditentukan olch para pemilik kaset atau lingkungan dimana kasct tersebut lersimpan. Kaset-kaset shalawat dan azan scrta pengajian umumnya tcrsimpan di masjid-masjid. Sedang kaset lagu kasidah dan ceramah agama kcbanyakan dimiliki dan tcrsimpan di radio amatir(radam)dan rumah-rumah penduduk.

Selain dari kclima jenis kasct tersebut. tcrdapat juga satu jenis yang bcrupa pakct khusus. Di dalamnya tcrdapat pclajaran "Dasar-dasar ke Islaman" dan beberapa pengajian al-qur'an. Pakct kasct ini diberi judul "Dirasah Islamiyah".

Kasct dalam bentuk pakct ini. ditemukan scbanyak 4 pakct, 3 dianlaranya di Sabbangparu Palopo dan 1 paket ditemukan di Bajoe Bone. Jumlah ini sangat minim dan masih mcrupakan barang langka, karena disamping tidak dijual di pasaran bebas, harganyajuga mahal untuk variasi. adayangmembahasmasalah aqidah, akhlaq, syariah (fighi) scjarah dan ada juga yang menyangkut pembinaan umat secara kesciuruhan.

Variasi kasct yang demikian itu, sesungguhnya diangkat dari gambaran kondisi rcalitas umat Islam dewasa ini, seperti yang disinyalir oleh A.M. Syacfuddin, bahwa "Tidak scdikil dari umat Islam yang belum mengerti Islam, bahkan masih banyak yang tidak bisa membaca dan mengetahui Alqur'an. Tcrbclakang dalam bidang kchidupan tcrutama dalam bidang pendidikan, ilmu pengctahuan \& tcknologi. (A M Saet'uddin 1987 : 172).

Untuk kasct ccramat agama, maleri isinya icrgambar pada topik yang diiempelkan di sampul muka sctiap kaset. Dalam satu kasct bcrisi salu topik dan isinya mcmbahas topik yang diangkat. Bcrbcda dengan kaset lagu qashidah yang me- 
nampilkan topik umum pada sampul muka dan di dalamnya tcrdapat lagi sub-sub atau topik-topik yang beragam.

Kaset keagamaan dalam bcntuk ceramah untuk bidang aqidah, topiknya seperti: Perang Aqidah, Allah itu Ada, Berkah Allah, Kiamat, Cobaan Hidup, Bila Ajal Tiba dan lain-lain. Bidang syariat/fiqhi sepcrti : Ramadhon dan Idul Fitri, Mari Tunaikan Haji, Hak-Hak Muslim, Bila Do'a Tak Tcrjawab, Taubat, Sirkuit Celaka, Bisnis Yang Mcnguntungkan dan sebagainya. Topik yang diangkat di bidang akhlaq, scperti : Membina Keluarga Bahagia, Para Kckasih Allah, Dusta dan Akibatnya, Bila Alam Mulai Bicara. Topik sejarah, seperti : Nabi Sulaiman dan Ratu Bulqis.Nabi MusadanFiraun.Pembaharuan yang Dibawah oleh Rasulullah SAW., dan topik yang menyangkut pembinaan umat, sepcrti : 10 Golongan Musuh Iblis, Pilar Pilar Dunia I, Pahala dan Dosa, Pilar-Pilar Dunia II, Hak-hak Hidup Beitetangga Mcnurut Ajaran Islam, Mcnjauhi Tujuh Perkara yang Merusak, Cara Mendidik Anak, Dasar dan Tujuan Hidup Muslim, Harta Wanita dan Tahta.

\section{IV}

Hampir scmua kaset keagamaan yang beredar di lokasi penelitian berasal dari Jakarta, terutama kaset ceramah. Scdikit diantaranyayang diproduksi secaralokal, baik oleh radam (radio amatir) maupun oleh individu-individu.

Rekaman kaset produksi lokal jumlahnya sangat terbatas, karena memang bukan untuk dikomersilkan, tetapi sematamata untuk kepentingan da'wah. Berbeda halnyadengan yang didatangkan dari Jakarta yang memang sengajamemproduksi secara besaran, karena disamping untuk tujuan da'wah juga ada nilai komersilnya.

Paramuballigh yang mengisi suara pada kaset-kaset itu, adalah tokoh-tokoh agama yang memang sudah terkenal, baik di tingkat nasional maupun di tingkat regional dan lokal. Untuk tingkat nasional, seperti Ustaz K. H. Zainuddin MZ., Ustaz K.H. Syukron Ma'mun, Ustaz K.H.Kasim Nurseha, dll. Tokoh agama di tingkat regional yang ada kasetnya di lokasi penelitian adalah Ustaz K.H. Ambo Dalle, Ustaz K.H. Muhammad Abduh Pabbaja dan KHM Yunus Marratan. Sementara itu untuk di tingkat lokal diambil dari pemuka agama setempat, seperti Ustaz K. H. Muh. As'ad di Palopo Luwu.

Ceramah agama yang dilantungkan oleh para tokoh agama melalui kaset mendapat tempal lersendiri di kalangan masyarakat. Namun demikian padakcnyataannya karena masalah yang diangkat menyentuh langsung dengan apa yang dialami masyarakat, sekalipun permasalahan itu tidak persis sama, dalam arti tcrdapat perbedaan. Oleh Parsudi Suparlan menyebutkan bahwa "Secara garis besamya antara lain disebabkan oleh perbedaan tingkat perkembangan kebudayaan dan masyarakatnya, oleh sifat kependudukannya dan oleh keadaan lingkungan alam dimana masyarakat itu hidup." (Suparlan 1986 : 61). Hampir tiada hari yang lewat tanpa alunan suara para ustaz, baik yang dipancarkan melalui radio amatir, di masjid-masjid maupun di rumah-rumah penduduk dan kios/toko.

Waktu-waktu pemutarannya terdapat 2 pola; pertama, ada yang memutar secara tetap (routin) pada waktu tertentu; kedua, ada yang memutar pada saat dibutuhkan artinya sesuai kebutuhannya. Pola kedua, 
pcmularannya dilakukan di rumah-rumah pcnduduk atau di tempat kerja, sepcrti kios/ toko dan di perahu motor.

Kalau yang sudah terpaket, sepcrti di radio amatir menghabiskan waktu dalam satu kali pemutaran atau penyiaran mulai dari 60 menit hingga 120 menit (2 jam). Scdang di masjid sckitar 20 menit. Tetapi bagi yang tidak tcrprogramkan, sepcrti yang terjadi di rumah-rumah penduduk dan tempat kerja, pemutarannya tidak menentu dan bcrdasar pada kebutuhan masingmasing.

Pada umumnya ccramah agama di dalam kaset mcnggunakan bahasa Indonesia, kecuali kaset lokal. Pcnggunaan bahasa Indonesia ini merupakan pilihan yang tcpat, karena sangat mcmungkinkan bisa dipahami secara luas oleh para pendengar, apalagi sudah menjadi bahasa rakyat.

Kebanyakan ustaz monggunakan gaya bahasa yang ringan, mudah dipahami, schingga pesan-pesan da'wah dengan mudah dikomunikasikan. Gaya bahasa yang ditampilkan juga menjadi salah satu l'aktor daya tarik tersendiri, apalagi jika discrtai dengan ramuan humor yang menyegarkan. sepcrti yang biasa dilampilkan oleh para ustaz yang sudah berlcvel nasional.

Selain gaya bahasanya yang ringan, dipcrkuat pul a dengan dukungan logika yang scderhana. Maksudnya, di dalam pengungkapannyatcrdapathubungan-hubungan rasional. Ini dilihat pada saat mengungkapkan pokok-pokok pikiran dengan argumentasi yang jitu, dan juga pada sistcmatikanya. untuk yang tcrakhir ini (sistcmatika) sckalipun nampaknya bclum ada kescragaman, tetapi tidak bcrarti penyajian da'wanya menyalahi aturan, karena sampai sckarang bclum tcrdapat aturan khususyang disepakali.

Penyebutan ayat-ayat alqur'an, alhadits rasulullah, hikmah-hikmah ataupun kissahkissah kadang dijadikan sebagai landasan pembahasan yang kemudian memperhadapkannya dengan masalahan-masalahan sosial (Lihat Parsudi Suparlan 1986 : 63). Kadang juga dijadikan sebagai dalil yang bisa mempcrkuat argumentasi atau pcrnyalaan. Begilupula untuk bisa mempengaruhi pendengar agar lebih pcrcaya dan meyakini isi pesan da'wah yang didengarnya.

Scmua ini dilakukan sebagai pelaksanaan misi da'wah yang merupakan kelanjutandari misi risalah Muhammad SAW dan dalam rangka mencgakkan agama Allah di lengah-tcngah masyarakat (Q.S 3:103, 104,42: 13 - 15).

Tcrscbarnya kascl-kaset kcagamaan mcnunjukkan adanya gejala baru dalam perubahan pola da'wah yang sclama ini dilakukan. Kehadirannya cukup banyak membantu dalam mcnycbarluaskan syi'ar agama. apalagi jangkauannya sudah sangat jauh sampai kc pclosok-pclosok, sehingga khalayak memungkinkan unluk menikmatinya.

Matcri isi yang ditampilkan menyentuh pcrmasalahan masyarakat, khususnya mcnyangkul kehidupan kebcragamaannya. Hal lersebul membual ada pcrsambungan diantara pendengar dengan ccramah dalam kaset, sckalipun penyajinya tidak tampak atau hadir di tengah-tcngah mcrcka.

Sckalipun kaset-kasct kcagamaan secara kuantitas masih sangat tcrbatas, namun secara kualitas kebanyakan sudah sangat mcyakinkan. Indikasinya tcrlctak pada 
kemampuan mengkomunikasikan pesan da'wah dalam bentuk sajian yang menarik, sehingga nampak tidak menjenuhkan pendengarnya.

Jika pola da'wah seperti ini berkembang terus, minimal bisa bertahan, maka dapat diindikasikan scbagai suatu kcber-

\section{DAFTAR BACAAN}

Craib, IAIN

Teori-teori Sosial

Moderen,

Jakarta: Rajawali

Sacfuddin, AM

1987 Disekularisasi Pemikiran

Landasan Islamisasi B an-

dung : Mizan

Suparlan, Persudi

Masalah-masalah Sosial \&
llmu Sosial Dasar di dalam
Widjaya (Ed) "Manusia Indo-
nesia Individu Keluarga dan
Masyarakat. Jakarta : Akade-
mika Prcssindo Cet.I.

hasilan. Dan jika terjadi sebaliknya, terlalu ceroboh untuk dikatakan sebagai kegagalan, karena belum ditelusuri lebih jauhmengenai dampak yang ditimbulkannya. Oleh karena itu, penelitian lebih jauhmengenai masalah tersebut perlu dilakukan pada masa datang.
Al Rasyid, H Harun

1986/1987 Pedoman Dakwah Bagi Muballigh dan Khotib Jakarta : Ditjen Bimas Islam \& Urusan Haji

Susanto, Astrid S. 1975 Pendapat Umum. Bandung : Bina Cipta, Cet.I.

Departcmen Agama RI Al Qur'an \& Terjemahannya Jakarta :

No. 9 Th. IV Januari / Juni 1993 